\title{
Identidade dos docentes em formação: quem são os futuros professores de matemática?
}

\author{
Identity of student teachers: \\ who are the future \\ mathematics teachers?
}

\author{
Beatriz Gomes NADAL ${ }^{1}$ \\ Mary Ângela Teixeira BRANDALISE ${ }^{2}$
}

\begin{abstract}
RESUMO: Este artigo apresenta uma pesquisa realizada em uma universidade pública sobre o perfil dos acadêmicos do curso de licenciatura em Matemática. A tematização do perfil dos professorandos em formação desencadeou uma discussão sobre a profissão docente junto a professores e alunos do Curso, contribuindo para sua reformulação e para a constituição da identidade profissional, ao mesmo tempo em que possibilitou a vivência de práticas interdisciplinares e contextualizadas de ensino e aprendizagem aos alunos das disciplinas de Estatística e Didática. A coleta de dados inicial, feita através de um questionário com perguntas abertas e fechadas, aplicado a 241 alunos, revelou o perfil sócio-econômico-educacional e cultural dos acadêmicos, bem como suas expectativas em relação ao Curso, trazendo significativas contribuições. A vivência com os alunos de princípios apregoados foi fundamental para sua aprendizagem e constituição de uma nova identidade e cultura profissional.
\end{abstract}

Palavras-chave: identidade profissional, formação de professores, licenciatura em matemática

ABSTRACT: This article presents a research done in a state university about the profile of the undergraduate students in the course on Teaching Mathematics. While doing the profile of the student teachers, discussions took place about the teaching profession with professors and course students which contributed to reformulating it and to build a professional identity. At the same time it was an opportunity to experience

${ }^{1}$ Mestre em Educação pela UEPG. Professora Assistente do Departamento de Métodos e Técnicas de Ensino da Universidade Estadual de Ponta Grossa. E-mail beatriz@nadal.com.br

${ }^{2}$ Mestre em Educação pela UEPG. Professora Adjunta do Departamento de Matemática e Estatística da Universidade Estadual de Ponta Grossa. E-mail branda@brturbo.com.br

Olhar de professor, Ponta Grossa, 8(2): 65-75, 2005. 
interdisciplinary and contextualized teaching and learning for the students doing Statistics and Didactics. The initial collection of data, done with the help of open and closed questions in a questionnaire, applied on 241 students, revealed a social-economiceducational and cultural profile of the students as well as their expectations concerning the course. All this brought significant contributions. The experience with the students who had strong principles was fundamental for their learning and building up of a new identity and professional knowledge.

Key words: professional identity, teacher education, degree in teaching mathematics

\section{INTRODUÇÃO}

O presente trabalho refere-se a uma pesquisa desenvolvida em uma universidade pública, num curso de licenciatura em Matemática para tematização do perfil do quadro discente no contexto da profissionalização docente, face aos processos de formação de professores e reestruturação curricular no Curso de Licenciatura em Matemática.

Envolvendo professores e acadêmicos das disciplinas de Estatística e Didática, por meio de uma abordagem qualitativa, a pesquisa contemplou o levantamento e a tematização do perfil dos acadêmicos do referido curso, através de montagem, aplicação e tabulação dos dados na disciplina de Estatística, e de seu estudo e interpretação na disciplina de Didática. Desse modo, teve como objetivos: identificar o perfil dos professores em formação no curso de licenciatura em Matemática; tematizar o perfil discente junto ao quadro de acadêmicos, contribuindo assim para a sua cons-cientização; e colaborar com a constituição de uma nova cultura e identidade profissional.

\section{"PROFESSORDE MATEMÁTICA": UMA DINÂMICA EM CONSTRU- ÇÃO}

Num momento em que as sociedades tanto valorizam a educação, torna-se impossível não associar tal discussão à figura do professor. É inegável sua centralidade na agenda educativa, já que é através de sua prática que os objetivos escolares são concretizados. O professor que trabalha diretamente com o aluno em sala de aula é, antes de qualquer outro, o profissional que com maior força determina o processo educativo.

Ao mesmo tempo em que essa posição valoriza os docentes, também lhes atribui uma grande responsabilidade, motivo pelo qual é fundamental uma clara definição do papel dos professores frente ao ensino e à formação discente, bem como sobre o modo como deve se dar a sua formação a fim de que consigam realizar com êxito sua tarefa.

Nesse sentido, foi inegável a contribuição do Conselho Nacional de Educação quando, através das ações desenvolvidas no âmbito da 
reformulação das licenciaturas, realizou um chamamento das instituições formadoras para a temática.

Contudo, o teor dado pelo órgão às suas diretrizes e resoluções, bastante próximo da discussão acadêmica desenvolvida na área, não garante, por si só, a efetivação de uma formação docente coerente com as necessidades colocadas pelo contexto de ação profissional. Isso porque a simples observância pelas instituições formadoras, em suas matrizes curriculares, de princípios normativos, mesmo que lógicos do ponto de vista de uma nova perspectiva de formação, é insuficiente para se garantir que os processos de "reforma" se configurem como mudança qualitativa.

A mudança educacional pressupõe nova maneira de planejar, ensinar, organizar o conhecimento, avaliar etc. Daí o professor ter de aprender a fazê-lo segundo as novas bases propostas, o que significa que a mudança só se desenvolve dentro das escolas se for concretizada pelo professor. Por isso ela não pode ser imposta por decreto. Atenção especial precisa ser dada à dimensão pessoal pressuposta nesse processo, ou seja, o impacto que a nova proposta tem no modo de pensar e de agir dos professores (ALMEIDA, 1999, p. 254).

Ao discutir a questão da mudança educacional, referindo-se ao nível escolar, Almeida (op. cit.) faz perceber um processo que é coincidente em qualquer nível de ensino e siste- ma educacional, pois em todos eles o fator pessoal está sempre presente. Inúmeros estudos vêm demonstrando que o trabalho docente caracteriza -se como uma prática cujo caráter é de construção, exigindo do professor capacidade de análise e tomada de decisão; uma prática, portanto, em que as dimensões criativas e criadoras prevalecem sobre a dimensão técnica. Assim, a composição de um trabalho que por sua essência configurase como construção única, sofre toda a influência do professor, sujeito cuja posição é de centralidade nessa constituição.

Interessa-nos destacar, frente a tais afirmativas, o papel do professor na efetivação de mudanças. Sua configuração como sujeito central justifica-se não apenas pelo fato de ser ele o profissional cujo trabalho efetivará a prática idealizada/planejada, mas especialmente pelo fato de que o referencial teórico-prático desse professor, seus conhecimentos, crenças e valores influenciarão de modo especial o trabalho a ser construído, agindo como "filtros" capazes de produzir uma síntese própria e pessoal. Isso denota que, nos momentos em que mudanças estão em pauta, as percepções, aceitações e incorporações dos professores sobre as mesmas são determinantes.

Nessa perspectiva, o trabalho docente supõe uma ação que vai além de aspectos prescritivos, sendo atingido não apenas pela subjetividade desse professor, como também e es- 
pecialmente por sua cultura profissional. Referindo-se aos estudos de Chauí (1995) e Teixeira (2001), Nadal (2003, p.11), define a cultura profissional como "conjunto de representações, símbolos, significados, práticas que são partilhadas pelo grupo de professores e que participam da determinação de seu ser e fazer docente, em função da própria construção histórica desse ofício". A discussão sobre a cultura profissional remetenos a duas dimensões.

Uma primeira, já abordada, referese à finalidade da cultura em relação ao trabalho docente. Sarmento (1994) cita Ost (1989), para o qual a cultura cumpre o papel de "ajudar os indivíduos a superarem ansiedade e a incerteza". Também faz referência ao trabalho de Schein (1990), que defende a idéia de que a cultura docente possui uma funcionalidade, possibilitando ao profissional trabalhar com os problemas, internos e externos, por ele enfrentados. É possível inferir, a partir daí, que a cultura determinada o modo de atuação dos professores, sendo a maneira como trabalham e enfrentam seus problemas um reflexo da cultura profissional veiculada e aceita pelo grupo profissional, o que leva à sua aceitação e valoração pelos demais professores.

A segunda dimensão refere-se, por conseqüência, ao papel da cultura sobre a constituição do próprio professor. Também Ost (1989), citado por Sarmento (1994, p. 66), afirma que a cultura dos professores tem a finali- dade de "atribuir identidade ao grupo profissional". Pautados por uma cultura profissional que por sua efetividade no enfrentamento de dificuldades passa não apenas a ser aceita e utilizada, mas também a ser veiculada aos novos profissionais que ingressam na categoria, os professores vão construindo sua identidade.

A identidade docente não é um simples reflexo de uma cultura aprendida; mas, por outro lado, a sua construção não se faz pela negação dessa cultura, como evidencia Nadal, ao citar Libâneo:

Segundo Libâneo (2001, p. 68), a identidade profissional éo '[...] conjunto de conhecimentos, habilidades, atitudes, valores que definem e orientam a especificidade do trabalho de professor'. Os traços que definem a identidade profissional vão além do corpo de conhecimentos ou da dimensão técnica do ensino, pois abrangem posicionamentos tomados a partir dessa, produtos também da dimensão pessoal do profissional, de suas concepções, valores, visões de mundo, por reflexo da cultura profissional, dinamicamente ressignificada. (NADAL, 2003, p. 13)

Considerando-se o impacto da cultura sobre a constituição do ser e fazer docente, como também a dinâmica que lhe é inerente, já que os aspectos que a compõem estão em uma dinâmica constante, percebe-se sua 
centralidade diante dos processos de mudança.

Em se tratando das reformas, grandes mudanças de cunho externo, a cultura docente e a identidade profissional terão grande papel na percepção das propostas, na viabilidade ou não de sua aceitação, na maior ou menor importância que se dá à sua execução. Levando-se em consideração as inovações, mudanças localizadas de caráter interno, serão determinantes da potencialidade ou não de que os professores e suas instituições sejam geradores de mudanças, as quais, por partirem da realidade, necessidades e concepções dos professores, contarão com maior chance não apenas de êxito, como também de se configurarem como mudanças qualitativas.

A necessidade, então, de que se operem mudanças na formação de professores, a fim de que atuem como sujeitos impulsionadores de mudanças no quadro educacional, faz refletir sobre a cultura docente hoje existente, sobre a identidade profissional dos professores, os quais precisam constituir-se como sujeitos capazes de se posicionar frente ao cenário de reformas, participando em sua discussão, adaptação, implementação, avaliação e reformulação, como também como sujeitos capazes de conceber mudanças para responder aos anseios de seu exercício profissional.

No quadro educacional, os professores têm se configurado como elementos de resistência frente ao cená- rio de reformas, mas uma resistência muda e infértil. A negação feita por eles, frente às propostas externas, não tem fertilizado reflexões capazes de estimular uma avaliação coerente e o replanejamento das propostas em questão. Mudar sua participação, para que se configurem como sujeitos participativos não apenas nos processos externos, como também geradores de ações internas, pressupõe, provavelmente, uma nova cultura profissional.

Mudar a cultura profissional implica compreender de que modo ela é apropriada pelos profissionais. Sarmento (1994) apresenta um breve inventário dos autores que abordaram o assunto, dentre os quais destacamos os trabalhos de Denscombe (1982), para o qual o contexto de trabalho dos professores é determinante da transmissão da cultura profissional, e os realizados por Acker (1987), que destaca a origem social dos professores, a história da profissão e o mercado de trabalho.

Se a cultura profissional é determinante da identidade docente, se é transmitida pela categoria através de um conjunto de práticas, contextos e situações, mas se, do mesmo modo, o professor constitui sua identidade pela ressignificação e revitalização dessa cultura, atribuindo-lhe um caráter dinâmico e não meramente reprodutor, vemos como imprescindível a tematização da cultura profissional existente, para que ela possa emergir do nível inconsciente para o 
nível da consciência, avançando assim em direção aos desafios enfrentados pelos profissionais.

Nesse processo, tornam-se relevantes práticas que permitam estar em contato com a cultura docente como o conhecimento da realidade profissional, das representações e práticas dos profissionais e, também, da constituição desse grupo profissional.

Se a identidade do professor é resultante de uma composição entre o que ele idealiza ser, o que efetivamente é e como esse seu "ser" é percebido pelos outros, a segurança em relação à profissão e ao profissional que a exerce é essencial para a definição da sua identidade, do seu reconhecimento e esses, conseqüentemente, são fundamentais para o processo de profissionalização, pois o alavancamento de práticas rumo a essa conquista demanda consciência, por parte dos professores, de quem são eles ${ }^{3}$ hoje (enquanto categoria/grupo social), de seus papéis e daquilo que deles se espera. (NADAL, 2003, p. 14-15)

Da mesma forma, a autora complementa: "perceber a cultura profissional como processo permite compreender sua importância na constituição do novo professor buscado, na constituição do professor-profis- sional e um determinante ativo na construção da identidade profissional" (idem, p. 13). Percebe-se, aí, a relevância da conscientização dos formadores de professores sobre a base social da categoria e, de modo especial, daqueles que ingressam enquanto futuros profissionais, a fim de que os processos formativos partam de tal realidade concreta em direção à formação desejada. Percebe-se também a importância da conscientização dos professores em formação quanto ao seu próprio perfil, para que, conscientes da identidade vivida, possam confrontá-la com a identidade a ser construída. A consciência da distância entre nossa realidade e aquilo que desejamos é, sem dúvida, o primeiro passo em direção à transformação.

\section{A BASE SOCIAL DO PROFESSO- RADO: PERFIL DOS ACADÊMI- COS DE LICENCIATURAEM MA- TEMÁTICAESUA REPERCUSSÃO PARA OS PROCESSOS DE FOR- MAÇÃO}

As recentes discussões sobre a formação dos professores de Matemática se inserem no contexto de formação e exercício profissional evidenciado. O fato indica que problemáticas persistem na formação do Educador Matemático quando se trata do exercício profissional voltado para a

\footnotetext{
${ }^{3}$ Conhecimento da "base social da categoria", aqueles que constituem e integram o grupo profissional. 
melhoria da qualidade dos processos de ensino e de aprendizagem, ou seja, da formação para que tenham a Matemática como área de competência (D' AMBRÓSIO, 1996, p.13) no contexto da profissão.

O curso pesquisado também reflete a situação atestada, embora muitos avanços já se tenham sido percebidos. A clareza de que a formação é uma dinâmica complexa, paralelamente aos movimentos deflagrados nacionalmente, quer no âmbito das entidades, quer no âmbito das instâncias governamentais e gestoras, mobilizou o Colegiado do Curso a desencadear processos de construção coletiva de um novo projeto pedagógico, movimento no qual se inseriu a presente pesquisa.

As discussões e reflexões realizadas junto ao corpo docente apontaram que o perfil profissional buscado pela instituição é o de um professor para atuar nos três níveis de ensino, capaz de posicionar-se de forma consciente e crítica frente aos contextos sociais e educacionais, atuando com responsabilidade, ética e autonomia, através do sólido domínio dos conteúdos matemáticos e pedagógicos.

Na maioria dos casos há, nos cursos de licenciatura, a ausência de clareza quanto ao profissional que se deseja formar. Tal nebulosidade interfere na formação profissional, na medida em que as ações docentes não ficam articuladas nem entre si, nem em relação ao projeto pedagógico do curso, o que compromete a efetividade do trabalho realizado. É necessário, então, que os colegiados promovam uma discussão entre todos os formadores que atuam na licenciatura, a fim de que, a partir de tal estratégia, estabeleçam ações e atitudes comuns.

O conhecimento, por parte de todos os formadores, da postura de professor desejada, das capacidades para ele defendidas, é fundamental. Mas é preciso lembrar que a definição dessa identidade implica o conhecimento da base social da categoria, a ser tomada como ponto de referência da formação buscada. Por outro lado, o conhecimento do perfil acadêmico não pode, de modo algum, ser tomado como justificativa para formadores ou formandos minimizarem os processos pedagógicos. Ao contrário: à medida que trazemos uma realidade ao nível da consciência, debruçando-nos sobre ela, teorizando para compreendêla, é que podemos efetivamente trabalhar para sua mudança e avanço.

Através da pesquisa foi obtido um conjunto de informações significativas, que possibilitou apreender as características básicas dos acadêmicos do Curso. Trata-se de características gerais, que engendram significados diversos em sua relação com ações educativas, e que podem subsidiar o delineamento do perfil dos professorandos.

Os dados do estudo apresentaram uma média de idade do alunado de 22,6 anos. Os acadêmicos com até 20 anos somam $31 \%$ do total, $50 \%$ tem de 21 a 26 anos e os acima de 27 anos

Olhar de professor, Ponta Grossa, 8(2): 65-75, 2005. 71 
somam 19\%. Em relação ao sexo, 66\% dos acadêmicos são mulheres e 34\% homens. Esses dados ilustram uma realidade que pode ser observada em todo o país: a de que o magistério é uma profissão predominantemente feminina, ainda que na área da Matemática a participação dos homens seja representativa.

Do mesmo modo, a idade média de 22,6 anos indica um grupo predominantemente jovem. Esse quadro pode representar, por um lado, um perfil profissional com características ajustadas ao rápido, tecnológico e mutante cenário atual. Por outro lado, lembram tratar-se de uma geração que viveu, em sua formação básica, os anos iniciais de um processo pedagógico de mudanças cujos resultados indicam inúmeras dificuldades. Essa preocupação é reiterada por Marin (2004), quando diz: "A questão central a ser retomada aqui é a de que as crianças da 'geração 80' chegaram às salas de aula aos cursos de formação de professores e à pesquisa, ou seja, aos mestrados e doutorados".

No âmbito da procedência do alunado a grande maioria tem residência permanente em Ponta Grossa (71\%), Castro (12\%), e os demais (17\%) de outros municípios dos Campos Gerais. A moradia dos professorandos se dá, em sua maioria, em casa própria $(77 \%)$, sendo que $16 \%$ moram em casa alugada, $5 \%$ moram em casa cedida, $2 \%$ apresentam outras situações. Paralelamente ao fator moradia, apresenta-se o fator meio de transporte e, nesse caso, cerca da metade (52\%) dos acadêmicos utiliza transporte coletivo, $18 \%$ carro próprio, $12 \%$ transporte universitário, $6 \%$ moto, $6 \%$ a pé e $6 \%$ outros.

Quanto ao estado civil dos acadêmicos pesquisados, $70 \%$ são solteiros, $26 \%$ casados, 2\% divorciados ou desquitados e $2 \%$ vivenciam outras combinações familiares. Relacionando estado civil aos dados relativos à moradia e transporte, podemos inferir que os jovens estudantes são predominantemente solteiros e, assim, residem com seus pais, os quais já possuem casa própria. No fator transporte também não há "independência", pois a maioria dos alunos utiliza predominantemente o transporte coletivo.

Esses dados também podem ser compreendidos através da situação funcional dos pesquisados. Dos respondentes, $40 \%$ não trabalham, $24 \%$ trabalham em empresa privada, $7 \%$ são funcionários públicos, $8 \%$ são professores de escola pública, 3 \% são professores de escola privada, $4 \%$ exercem profissão liberal e 14\% atuam em outras profissões.

Contar com um quarto do alunado dedicando-se exclusivamente aos estudos, seja por opção ou por falta de oportunidade de emprego, é uma realidade que se faz cada vez mais rara nos cursos de licenciatura os quais, inclusive, tendem a ser maciçamente noturnos. Outro aspecto importante é o fato de que uma parcela muito pequena já exerce a docência, um reflexo provável da política de Estado, no 
Paraná, que extinguiu os cursos de magistério.

Entre os acadêmicos que trabalham, $66 \%$ declararam possuir renda entre um a quatro salários mínimos, evidenciando que o conjunto de entrevistados traduz um perfil de renda próximo ao da grande maioria da população economicamente ativa do país, que está entre um e cinco salários mínimos. Destes, $40 \%$ se inseriram no mercado de trabalho ente $14 \mathrm{e}$ 18 anos de idade.

No quesito escolaridade, é significativo relatar que a grande maioria dos alunos é proveniente de escolas públicas: $75,4 \%$ dos acadêmicos freqüentaram o ensino fundamental em escolas públicas e $77,6 \%$ o ensino médio em escolas da rede pública. Esses estudos realizaram-se prioritariamente no período diurno $(63 \%) \mathrm{e}$, talvez por isso, parte considerável desse alunado (47\%) não participou de cursos pré-vestibulares.

Reafirma-se, assim, uma realidade que também é nacional: a de que os cursos de formação de professores têm sido a opção das camadas mais populares, estudantes do ensino público. Para esses alunos, que dificilmente possuem acesso aos chamados "terceirões" e "cursinhos", a licenciatura pode representar a chance de acesso ao ensino superior, tendo em vista a menor relação candidato/vaga que se apresenta nesses cursos. Um dado importante a ser destacado é o de que $5 \%$ dos acadêmicos são provenientes da modalidade de ensino supletivo.

Para os alunos pesquisados, a formação em nível superior representa uma ascensão em relação a seus pais, cuja maioria (39\%) não concluiu o ensino fundamental: $11 \%$ o possuem completo e, apenas $22 \%$ possuem o ensino médio. O ensino superior é uma realidade para apenas $4 \%$ dos pais. Em relação às mães, os dados são levemente superiores, pois $31 \%$ delas não concluíram o ensino fundamental, $13 \%$ o possuem completo, $22 \%$ cursaram o ensino médio e $6 \%$ realizaram curso superior.

O cruzamento do nível de escolarização dos pais (cerca de 20\% com nível médio completo) com a ocupação predominante $(29 \%$ são professores em escolas públicas) comprova uma outra realidade, a de que a formação dos professores em nível superior ainda não é uma realidade. Os demais são profissionais liberais (16\%), empregados em empresa privada (15\%), empresários (8\%) e funcionários públicos (11\%).

Em decorrência da ocupação, percebe-se que a renda familiar é baixa, pois a grande maioria (73\%) concentra-se na faixa entre três a oito salários mínimos e $9 \%$ entre 1 a 2 salários mínimos. Apenas 10\% possuir renda familiar acima de 10 salários

$\mathrm{O}$ acesso às tecnologias de informação ainda é pequeno, pois apenas $39 \%$ possuem computador em casa, $58 \%$ dos acadêmicos têm apenas o curso de informática básica. Quanto à língua estrangeira, apenas $10 \%$ de- 
clararam ter conhecimento. A televisão, o rádio e a Internet são os meios de comunicação mais utilizados pelos acadêmicos para se manterem atualizados.

As preferências em relação a lazer e cultura são: música, cinema e vídeo, religião, esporte, leitura. Enquanto meio de informação, esta fica restrita à área específica. Quanto à prática de atividades físicas os dados revelaram que $29 \%$ não praticam nenhuma, $21 \%$ declararam fazer caminhadas, $17 \%$ declararam jogam futebol, $7 \%$ praticam xadrez e $19 \%$ preferem outras atividades.

Quando questionados sobre o motivo da opção pelo curso, $61 \%$ dos respondentes declararam tê-lo escolhido por considerarem que é o mais adequado às suas aptidões; $6 \%$ pela menor relação candidato/vaga; $4 \%$ pelo prestígio social/econômico; $3 \%$ por influência da família e amigos; 3 $\%$ por influência dos professores; e $23 \%$ por outros motivos. Os acadêmicos consideram que para a formação do professor de Matemática é fundamental a aptidão, uma formação específica e pedagógica sólida e uma formação permanente duração a atuação profissional.

\section{CONSIDERAÇÕES FINAIS}

O retrato dos acadêmicos da licenciatura em Matemática assemelha-se ao traçado em outras pesquisas desenvolvidas na área. Como exercício e processo de formação, essa tematização junto a alunos e professores deixou ver, claramente, o desconhecimento até então da identidade existente, associado à negação de muitos dados indicados.

Por parte dos alunos, a perplexidade apresentou-se especialmente relacionada aos quadros não tão favoráveis da profissão, nos aspectos social, econômico e cultural. Apesar deste ter sido, para a maioria, um dos primeiros momentos de tematização das questões da profissão em si, a força do imaginário que cerca a profissão é ainda muito forte, criando uma visão idílica do professor como pessoa que estaria acima de toda sorte de diversidade ou dificuldades, inclusive as de cunho material. Romper com uma visão até mesmo romântica da profissão através da conscientização sobre as dificuldades pelas quais passa o profissional do ensino no exercício da docência bem como em relação à necessidade de envolvimento e participação em diferentes instâncias para a reversão das dificuldades existentes, é uma meta que necessita continuar sendo perseguida.

Por parte dos docentes, a perplexidade apresentou-se relacionada à materialidade e efetividade dos quadros então conhecidos e sua repercussão para os processos de ensino desencadeados no interior do curso. No que diz respeito aos alunos, evidenciou-se sua dificuldade para visualizar o profissional docente na figura do professor de Matemática e 
do bacharel, assim como para encontrara alternativas capazes de superara as situações difíceis que repercutem na sala de aula, não apenas em decorrência do seu perfil, mas também por conta dele. Constatou-se, ainda, que os acadêmicos investigados têm uma visão em cerro ponto idílica ou fatalista em relação ao papel da universidade e da formação de professores no espaço da licenciatura.

Analisar o perfil dos acadêmicos da licenciatura em Matemática exige cuidado e profunda reflexão capaz de articular a gama de fatores envolvidos. O perfil aqui apresentado deve ser relacionado a muitas outras questões que concorrem para o fenômeno educacional e a formação de professores. Como se pôde observar, os licenciandos pesquisados compõem um universo de contrastes, de diferenças e de possibilidades que refletem a realidade da grande maioria do alunado dos Cursos de Licenciatura em Matemática no cenário brasileiro.

\section{REFERÊNCIAS}

ALMEIDA, M. I. Os professores diante das mudanças educacionais. In: BICUDO, M. A. V. SILVA JR. C. A. Formação do educador e avaliação educacional: organização da escola e do trabalho pedagógico, v. 3 (Orgs.). São Paulo: Unesp, 1999.

BICUDO, M. A. V. BORBA, M. de C. Educação matemática: pesquisa em movimento. São Paulo : Cortez, 2004.

BUSSAB, W. de O., MORETTIN, P. A. Estatística básica. 5.ed. São Paulo: Sarai- va, 2003.CONTRERAS, J. A autonomia de professores. São Paulo: Cortez, 2002.

CHAUI, M. Convite à Filosofia. 12. ed. São Paulo: Ática, 1999.

D’AMBRÓSIO, U. Educação Matemática: da teoria à prática. Campinas: Papirus, 1996.

DUBAR, C. A socialização: construção das identidades sociais e profissionais. Porto: Porto Editora, 1997.

MARIN, A. J. GIOVANNI, L. M. GUARNIERI, M. R. Formação e ação docentes: tempos sombrios os que se delineiam para o futuro. In: ROMANOWSKI, J. P. MARTINS, P. L. O. JUNQUEIRA, S. R. A. (Orgs.) Conhecimento local e conhecimento universal: práticas sociais: aulas, saberes e políticas. Curitiba: Campagnat, 2004.

MIZUKAMI, et al. Escola e aprendizagem da docência: processos de investigação e formação. São Carlos: EdUFSCar, 2002.

NADAL, B. G. Profissionalizaçao docente: a composição de uma (nova) cultura profissional. 2003. (mimeo)

SARMENTO, M. J. A vez e a voz do professor. Contributo para o estudo da cultura organizacional da escola. Porto: Porto Editora: 1994.

TEIXEIRA, L.H.G. Cultura organizacional e projeto de mudança em escolas públicas. Campinas: Autores Associados, São Paulo: UMESP: ANPAE, 2002.

UNESCO. O perfil dos professores brasileiros. Pesquisa Nacional. São Paulo: Moderna, 2004.

Encaminhado em: 20/06/05

Aceito em: 17/09/05

\footnotetext{
olhar de professor, Ponta
} Grossa, $8(2):$ 65-75, 2005. 